\title{
Toxicity Bioassay of some Essential Oil Vapour on Various Life Stages of Two-Spotted Spider Mite, Tetranychus urticae (Acari: Tetranychidae) under Laboratory Conditions
}

\author{
M. Shahrima Tasnin and M. Khalequzzaman ${ }^{1}$ \\ Received: 29th July 2015 / Accepted: $1^{\text {st }}$ December 2015
}

\begin{abstract}
ABASTRACT
A comparative efficacy of five essential oils (EOs) of cardamom (Elettaria cardamomum Maton), Cinnamon (Cinnamomum zeylanicum Blume), Clove (Syzygium aromaticum L.), Eucalyptus (Eucalyptus spp.), and Jasmine (Jasminum spp.) was assessed against two-spotted spider mite (TSSM), Tetranychus urticae. The mites were reared under laboratory conditions and oils were procured from market. Fumigation experiment was done in a glass jar making it airtight. The mortality of mites was recorded after 48 hours of treatment. The result showed that the most potent fumigant was cardamom with highest $L_{50}$ values $180.57 \mathrm{nlcm}^{-3}, 199.45 \mathrm{nlcm}^{-3}$ and $395.36 \mathrm{nlcm}^{-3} \mathrm{for}$ protonymph, deutonymph and adult respectively. Jasmine $\left(354.05 \mathrm{nlcm}^{-3}\right)$, cinnamon $\left(659.13 \mathrm{nl} \mathrm{cm}^{-3}\right)$ and eucalyptus (1033.7 $\mathrm{nlcm}^{-3}$ ) were least effective oils for protonymh, deutonymph and adult stages accordingly. All the oils used in the current study have a variable degree of toxicity on different stages of TSSM life cycle In case of all tested oils, protonymph showed 50\% mortality at lower doses(range of value was 180.57 to $354.05 \mathrm{nlcm}-3$ ) but adult needed two to three fold higher doses( range of value was 395.36 to $1033.7 \mathrm{nlcm}-3$ ) than protonymh. The result has revealed that, all these oils have great potentiality to be used as an acaricide in pests control program.
\end{abstract}

Keywords: adult, deutonymph, essential oils, protonymph, two-spotted spider mite

\section{INTRODUCTION}

Tetranychus urticae Koch is a notorious pest of economically important Agricultural crops as well as ornamental plants (Navajas et al., 1998). It has been reported to attack about 1200 species of plants (Zhang, 2003), of which more than 150 are economically important (Jeppson et al., 1975, Xie et al., 2006). It causes damage to sweet corn, beans, peas, hops, grapes, deciduous fruit trees, strawberries and many other fruit, vegetables, flowers and ornamental plants (Johnson and Lyon, 1991). The feeding effect of nymph and adults causes damage to the plants by reducing chloroplast, $\mathrm{CO}_{2}$ uptake, photosynthesis and transpiration (Sances et al., 1982). It is particularly dominant in intensive, high-yield cropping systems (Gorman et al., 2001; Ay et al., 2005). The economic threat posed by these mites is constantly increasing because of the development of pesticide resistance and the resurgence of mite population. These mites have evolved resistance to more than 80 acaricides to date and resistance has been reported to more than 60 countries.

Besides the problem of pest resistance, there is also concern about the high residues and toxicity of common miticides to humans. Thus, there is a need to find alternative control measures to suppress mite populations. Natural product like plant derived essential oils may be an excellent alternative of synthetic pesticides as they are 
environmentally safe and have low mammalian toxicity. In recent years essential oils have received much attention as pest control agents. The insecticidal, miticidal and broad spectrum activity of essential oils against various soft bodied pests has proven. Rosemary, Garlic, Jojoba, Thymus vulgeris, Lavendula officinalis, Eucalyptus camalduensis, Mentha longifolia, Salvia officinalis. Myrtus communis, and various other essential oils' acaricidal activity have been studied by many researches. Essential oils have multiple mood of action including antifeedant, repellant, molting and respiration inhibition, growth and fecundity reduction and killing effect (Akhtar and Isman, 2004; Alexenizer and Dorn, 2007). Although acaricidal activity of Eucalyptus has been tested, the efficacy of cardamom, cinnamon, clove and jasmine oil has not been studied yet. The objective of the study was to investigate the effect of these essential oils on different life stages of T. urticae under laboratory conditions.

\section{MATERIALS AND METHODS}

\section{Test Mites Sources}

The research project had been carried out in the Research Laboratory of Department of Zoology, University of Rajshahi, Bangladesh from April, 2013 to June, 2014. T. urticae Koch was collected from egg plants cultured at the institute of biological science, Rajshahi University, Bangladesh. Bean seeds were planted in the earthen pots at the rate of 4-5 seeds per plot and seedlings were infested with T. urticae Koch.

\section{Laboratory Culture}

To increase the number of T. urticae, mites were reared on excised leaf disc in the laboratory of department of Zoology of Rajshahi University at $25^{\circ} \mathrm{C}$ temperature and $65 \pm 2$ relative humidity. Leaf discs were made with fresh bean leaf without mite infestation. The leaf discs were placed on cotton bed in a petri dish $(5 \mathrm{~cm} \times 1 \mathrm{~cm})$ facing under surface upward. The cotton bed was kept wet by soaking with distilled water twice daily to keep leaf discs fresh and to avoid the migration of mites to the lower leaf surface. With the aid of a binocular microscope and with fine paint brush, 30 ovipositing females were transferred to the petri dish and allowed to lay egg for 24 hours. Before transferring mites to the leaf discs for laying eggs, the leaf discs were checked under microscope to avoid the presence of predatory insects and mites.

\section{Essential Oils}

Five essential oils, cardamom, cinnamon, clove, eucalyptus and jasmine procured from market were used at different concentration on three different stages- protonymph, deutonymph, and adult of T. urticae Koch.

Cardamom oil: oil extracted from the $E$. cardamomum is mainly composed of 1 , 8 -cineole (60 to $75 \%$ ), $\alpha$-terpinyl acetate $(31.3 \%$ ) limonene $(11.6 \%)$ and other minor components. (Lewis, et al., 1966; Salzer, 1975; Wijesekera and Jayawardena, 1973; Korikanthimath, et al., 1999).

Cinnamon oil (C. zeylanicum Blume): The bark oil consists of cinnamaldehyde (8090\%), eugenol, eugenol acetate, cinnamyl acetate, cinnamyl alcohol, methyl eugenol, benzaldehyde, benzyl benzoate, linalool, monoterpene, hydrocarbon, caryophyllene, safrole and others, such as pinene, phyllandrene, cymene and cineol (Health, 1978).

Clove oil (S. aromaticum L. Merrill et al., and Perry): The major component of clove bud oil is composed of eugenol (70-95\%), eugenol acetate $(17 \%)$, and $\beta$-caryophyllene (12-15\%) and lesser amounts of other components such as benzyl alcohol, but the proportions vary widely (Nurdjannah and Bermawie, 2001)

Eucalyptus (Eucalyptus spp.): The oil contains 1, 8-cineole (56.92\%), cryton (5\%), a-terpineol 
(4.44\%), pcymene $(5.45 \%)$ and others components.

Jasmine (Jasminum spp.): The volatile constituents consist of benzyl acetate, indole, E-E- $\alpha$-farnesene, Z-3-hexenyl benzoate, benzyl alcohol, linalool, and methyl anthranilate (Edris et al., 2008).

\section{Fumigant Toxicity Bioassay}

A glass jar (12 cm height $\times 5 \mathrm{~cm}$ diameter $)$ was used as an experimental unit in fumigation bioassay. Studies were carried out separately for the protonymph, deutonymph, and the adult stage. Preliminary tests were done to choose the right doses. The oils were used in this method with small cotton balls. Each cotton ball received different amount of essential oils. The oils were used by Hamilton micro syringe in micro liter $(\mu 1)$ unit and latter converted into nano liter (nl) unit. The tests were replicated 4 times and each replicate contain 30 mites (a random selection from both sexes) of the same age from the stock colonies were transferred onto excised bean leaves using a soft paint brush and allowed to settle for half an hour before being exposed to the essential oil. The doses of five essential oils used against various life stages of T. urticae is shown on Table 01. To prevent direct contact between mites and tested oils, the desired oil quantities were applied on the small cotton balls were attached to the lower surface of petri dish. Each Petri dish was placed inside the specimen jar. The jar then capped with lid and sealed with tape to prevent any loss of essential oils. The control consisted of similar set up but without essential oils. Mortality was recorded after 48 hours of exposure. Mites incapable of moving after a slight touch with a fine brush were considered as dead.

\section{Data Analysis}

The mortality percentage was corrected using Abbott's formula (Abbott, 1925; Busvine, 1971).The observed data then subjected to probit analysis according to Finney (1947) and Busvine (1971) using a software developed in the Department of Agriculture and Environmental Science, University of Newcastle Upon Tyne, United Kingdom, the software adapted the traditional calculations to automatic computation. Heterogeneity was tested by chi-squared test. If the probability is greater than $5 \%$ an automatic correction of heterogeneity is introduced. The program also calculated confidence limits for $\mathrm{LD}_{50}$.

\section{RESULTS AND DISCISSION}

The present study demonstrate for the first time that the essential oil vapour of cardamom, cinnamon, clove, eucalyptus and jasmine possess fumigant toxicity on three different stages of two-spotted spider mite, T. urticae Koch. It has been seen that different doses of essential oils of these five essential oils caused varied mortality in protonymph, deutonymph and adult stages. The result showed that the most toxic oil on protonymph deutonymph and adult was cardamom which showed highest mortality in lower doses where the $\mathrm{LC}_{50}$ values were $180.57 \mathrm{nlcm}-3,199.45 \mathrm{nlcm}-3$ and $395.36 \mathrm{nlcm}-$ 3 respectively. In contrast Jasnine, Cinnamon and eucalyptus were least effective oils where the $\mathrm{LC}_{50}$ values were 354.05659 .13 and 1033.7 for protonymph, deutonymph and adult stage accordingly $\mathrm{LC}_{50}$ values of tested essential oils on three stages of T. usticae is demonstrated in Table 01 . For the protonymph stage, the calculated doses of cardamom, eucalyptus, cinnamon, clove, and jasmine oils at which 50\% mortality of mites occurred were 180.57, 293.35, 348.33, $349.45,354.05 \mathrm{nlcm}^{-3}$ respectively. The toxicity order was cardamom $>$ eucalyptus $>$ cinnamon $>$ clove $>$ jasmine. In case of deutonymph stage 199.45, 455.84, 472.58 , 541.01, $659.13 \mathrm{nlcm}^{-}$ ${ }^{3}$ of above mentioned oils were needed to kill half of the tested population respectively where toxicity order was cardamom $>$ clove $>$ jasmine $>$ eucalyptus $>$ cinnamon. 
Table 01: Different doses of five essential oils used on three stages of $T$. urticae

\begin{tabular}{cccc}
\hline \multirow{2}{*}{ Oils } & \multicolumn{3}{c}{ Doses $\left(\mathrm{nlcm}^{-3}\right)$} \\
\cline { 2 - 4 } & protonymph & deutonymph & adult \\
\hline \multirow{4}{*}{ cardamom } & 135.9 & 67.9 & 360.9 \\
& 101.9 & 51 & 279.2 \\
& 67.9 & 34 & 233.5 \\
cinnamon & 34 & 17 & 169.9 \\
\hline \multirow{4}{*}{ clove } & 212.3 & 318.5 & 382.2 \\
& 169.9 & 254.8 & 318.5 \\
& 127.4 & 191.1 & 254.8 \\
& 84.9 & 127.4 & 191.1 \\
\hline \multirow{3}{*}{ eucalyptus } & 276 & 318.5 & 424.6 \\
& 148.6 & 254.8 & 339.7 \\
& 84.9 & 191.1 & 254.8 \\
& 169.9 & 127.4 & 169.9 \\
\hline \multirow{3}{*}{ jasmine } & 127.4 & 424.6 & 339.7 \\
& 42.9 & 339.7 & 254.8 \\
& 127.5 & 254.8 & 169.9 \\
\hline
\end{tabular}

The $\mathrm{LC}_{50}$ values after 48 hours of treatment for adult stage were 395.36, 510.53, 593.39, 657.47, and $1033.7 \mathrm{nlcm}^{-3}$ where toxicity order was cardamom $>$ cinnamon $>$ jasmine $>$ clove $>$ eucalyptus. From these data, it can clearly be seen that, to kill $50 \%$ population of protonymph, less amount of oils were needed than deutonymph and adult.

It is appeared from the Table 02 that all the oils have varied degree of mortality on each stages of TSSM. The toxic effect of all these oils on $T$. urticae observed in our study could be due to combine action of different active components of various oils. Miresmailli et al., (2006) has studied major components of Rosmarinus officinalis essential oil and contribution of individual component to the mortality of $T$. urticae on bean and tomato leaf. The major constituens of $R$. officinalis was 1.8 cineole (31.5\%), camphene $(8 \%)$, limonene $(3.7 \%)$, $\alpha$-pinene (17.5\%), $\beta$-Pinene (6.8\%). The study also demonstrated that 1,8 cineole, $\alpha$-pinene, $\beta$-Pinene responsible for $88( \pm 4.8), 32( \pm 4.8)$ and 16( \pm 7.4$)$ percent mortality of T. urticae Koch on bean leaf respectively. In the current study cardamom oil had been used which reported to contain $65-75 \%$ of 1,8 cineole which considerably vary according to variety, region and age of the product (Lewis et al., 1966; Salzer, 1975; Wijesekera and Jayawardena, 1973; Korikanthimath et al., 1999). In the laboratory trial, cardamom oil reported to perform highest mortality with considerably lower doses on all three stages of T. urticae . $\mathrm{LC}_{50}$ values were $180.57,199.45$ and $395.36 \mathrm{nlcm}^{-3}$ for protonymph, deutonymph and adult stage respectively. Eucalyptus oil used in experiment was considerably less effective than cardamom oil in all three stages where $\mathrm{LC}_{50}$ were 293.35, 541.01 and $1033.7 \mathrm{nlcm}^{-3}$ for above mentioned stages respectively. This oil has been reported to contain 62 percent 1,8 cineole (Sastri, 1953), 
although the percentage also recorded to vary in response to various factors. Eugenol is another major component of different essential oil. Eugenol separated from Ocimum suave applied on four beetle species Sitophilus granarium, Sitophilus zeamais, Tribolium castaneum and Prostephanous truncates showed that the doses $1 \mathrm{ml} / \mathrm{kg}$ of grain killed all beetle within 1 hour (Obeng and Reichmuth, 1997). Cinnamon and clove oil tested on TSSM had moderate toxicity. Eugenol is a major constituents of cinnamon leaf that account approximately $78 \%$ of total volatile (Ayala-Zavala et al., 2008) and in clove bud oil the amount of eugenol is 7095\% (Nurdjannah and Bermawie, 2001). Both the oils had shown almost similar efficacy for protonymph when 348.33 and $349.45 \mathrm{nlcm}^{-}$ ${ }^{3}$ oil were needed to kill $50 \%$ tested mites by cinnamon and clove respectively. However in protonyph and deutonymph stage their toxicity varies significantly. In these stages cinnamon was more effective than cardamom and its needed 100 to $200 \mathrm{nlcm}^{-3}$ less doses than clove oil. Their $\mathrm{LC}_{50}$ values were 659.13 and $455.84 \mathrm{nlcm}^{-3}$ for deutonymph and 510.53 and $657.47 \mathrm{nlcm}^{-3}$ for adult. Among five oils tested on T. urticae, the chemichal constituent of Jasmine oil was completely different from all other oils. The volatile oil contains benzyl acetate, indole, E-E- $\alpha$-farnesene, Z-3-hexenyl benzoate, benzyl alcohol, linalool, and methyl anthranilate (Edris et al., 2008). The $\mathrm{LC}_{50}$ of Jasmine oil on protonymph, deutonymph and adult stage were $354.05,472.58$, and $593.39 \mathrm{nlcm}^{-3}$ accordingly which apparently similar with cinnamon and clove.

Table 02: $\mathrm{LD}_{50}, 95 \%$ confidence limits and $\chi^{2}$ value of five tested essential oils

\begin{tabular}{clcccc}
\hline \multirow{2}{*}{ Stages } & \multicolumn{1}{c}{ Oils } & LD $_{50}$ & \multicolumn{2}{c}{$95 \%$ confidence limits } & \multirow{2}{*}{$\chi^{2}$ value (at 2 df) } \\
\cline { 4 - 5 } Protonymph & Cardamom & 180.5702 & 113.960 & 286.112 & 0.583 \\
& Cinnamon & 348.3333 & 238.060 & 509.685 & 0.877 \\
& Clove & 349.4521 & 251.661 & 485.241 & 5.753 \\
& Eucalyptus & 293.3488 & 169.317 & 508.237 & 3.975 \\
& Jasmine & 354.0452 & 248.264 & 504.897 & 2.439 \\
\hline \multirow{5}{*}{ Deutonymph } & Cardamom & 199.4529 & 55.780 & 713.182 & 0.348 \\
& Cinnamon & 659.1277 & 279.706 & 1553.23 & 0.555 \\
& Clove & 455.8377 & 301.127 & 690.035 & 0.213 \\
& Eucalyptus & 541.0162 & 380.837 & 768.564 & 3.444 \\
& Jasmine & 472.5809 & 287.809 & 775.974 & 0.203 \\
\hline \multirow{5}{*}{ Adult } & Cardamom & 395.3591 & 318.596 & 490.618 & 1.894 \\
& Cinnamon & 510.5302 & 380.024 & 685.852 & 0.546 \\
& Clove & 657.4658 & 429.150 & 1007.25 & 2.275 \\
& Eucalyptus & 1033.7 & 281.592 & 3794.62 & 0.463 \\
& Jasmine & 595.3873 & 250.730 & 1413.81 & 1.274 \\
\hline
\end{tabular}




\section{CONCLUSION}

The finding represented that, all the oils (cardamom, cinnamon, clove, eucalyptus and jasmine) used in the current study have a variable degree of activity on different stages of TSSM life cycle. Cardamom have the most potent toxicity while cinnamon, clove and jasmine have moderate toxicity and the efficacy of eucalyptus fluctuate greatly at different stage of TSSM. Generally protonymph represented lower $\mathrm{LC}_{50}$ than the deutonymph and adult that means protonymph are more susceptible than deutonymph and adult. The susceptibility order is protonymph. $>$ deutonymph $>$ adults. It is quite obvious that the toxic properties of the selected EOs are very much effective for checking the population builds up of T. urticae.
Although acaricidal effect of essential oils has been proven but very little is known about the exact site of action of plant essential oils on TSSM. Further investigation is needed to find out which components are exactly responsible for certain action and what mechanism play vital role to affect negatively the growth of $T$. urticae to develop essential oil based acaricides commentially.

\section{ACKNOWLEDGEMENT}

The author would like to thank the Chairman of the Department of Zoology, University of Rajshahi, Bangladesh to permit her using all the lab facilities during carrying out research.

\section{REFERENCES}

Abbott, W.S. (1925). A method of computing the effectiveness of an insecticide. Journal of Economic Entomology 18: pp. 265-267. http://dx.doi.org/10.1093/jee/18.2.265a

Akhtar, Y., and Isman, M.B. (2004). Comparative growth inhibitory and antifeedant effects of plant extracts and pure allelochemicals of four phytophagous insect species. Journal of Applied Entomology 128: pp. 32-38. http://dx.doi.org/10.1046/j.1439-0418.2003.00806.x

Alexenizer, M., and Dorn A. (2007). Screening of medicinal and ornamental plants for insecticidal and growth regulating activity. Journal of Pest Science 80: pp. 205-215. http://dx.doi. org/10.1007/s 10340-007-0173-x

Ay, R., Kelü, E. S., and Karaca Ü. (2005). Response to some acaricides of the two-spotted spider mite (Tetranychus urticae Koch) from protected vegetables in Isparta. Turkish Journal of Agriculture and Forerstry 29: pp. 165-17.

Ayala-Zavala, J. F., Soto-Valdez, H., González-León, A., Álvarez-Parrilla, E., Martín-Belloso, O., and González-Aguilar,G. A., (2008). Microencapsulation of cinnamon leaf (Cinnamomum zeylanicum) and garlic (Allium sativum) oils in $\beta$-cyclodextrin. Journal Inclusion Phenomena and Macrocylic Chemistry 60: pp. 359-368. http://dx.doi.org/10.1007/s10847-007-9385-1

Busvine, J.R. (1971). A critical review of the techniques for testing insecticides. Commonwealth Agricultural Buereux, London. pp. 345

Edris, A. E., Chizzola R., and Franz, C. (2008). Isolation and characterization of the volatile aroma compounds from the concrete headspace and the absolute of Jasminum sambac (L.) Ait. (Oleaceae) flowers grown in Egypt. European Food Research and Technology 226(3): pp. 621-626. http://dx.doi.org/10.1007/s00217-007-0623-y 
Finney, D. J., (1947). Probit Analysis: a statistical treatment of sigmoid response curve. Cambridge University Press, London. pp. 333.

Gorman, K., Hewitt, F., Denholm, I., and Devine, G. J. (2001). New developments in insecticide resistance in the glasshouse whitefly (Trialeurodes vaporariorum) and the two-spotted spider mite (Tetranychus urticae) in the UK. Pest Management Science 58: pp. 123-130. http://dx.doi.org/10.1002/ps.427 PMid:11852636

Heath, H. B., (1978). Flavour technology: profiles, products, applications. AVI Publishing Company. (ISBN 0-87055-258-9)

Jeppson,L. R., Keifer, H. H., and Baker, E. W. (1975). Mites injurious to economic plants. University of California Press, Berkeley, CA. pp. 458.

Johnson, W. T., and Lyon, H. H., (1991). Insects that feed on trees and shrubs (2 ${ }^{\text {nd }}$ edn). Comstock Publishing/Cornell University Press, Ithaca, NY. pp. 468-470.

Korikanthimath, V., Ravindra Mulge, S., and John Zachariah, T. (1999). Variations in essential oil constituents in high yielding selections of cardamom. Journal of Plantation Crops. 27 (3): pp. 230-232.

Lewis, Y. S., Nambudiri, E. S. and Philip, T. (1966).Composition of cardamom oils. Perfume Essential Oil Research. 57: pp. 623.

Miresmailli, S., Brandbury, R., and Isman M.B. (2006). Comparative Toxicity of Rosmarinus officinalis L. essential oil and blends of its major constituents aganinst Tetranychus urticae Koch (Acari: Tetranychidae) on two different host plants. Pest Management Science. 62: pp. 366-371. http://dx.doi.org/10.1002/ps.1157 PMid:16470541

Navajas, M. (1998). Host plant associations in the spider mite Tetranychus urticae (Acari: Tetranychidae): insights from molecular phylogeography. Experimental and Applied Acarology. 22: pp. 201-214. http://dx.doi.org/10.1023/A:1006062214318

Nurdjannah, N., and Bermawie, N. (2001). Hand book of herbs and spices. Woodhead Publishing Ltd. Orchard, I. http://dx.doi.org/10.1080/096708797229040

Obeng-Ofori, and D.,Reichmuth, C. (1997). Bioactivity of eugenol, A major component of essential oil of Ocimum suave (Wild.) against four species of stored-product Coleoptera. International Journal of Pest Management. 43 (1): pp. 89-94

Salzer, U. J. (1975). Analytical evaluation of seasoning extracts (oleoresins) and essential oils from seasonings. International Flavour Food Add. 6(3): pp. 151

Sances, F. V., Toscano, N. C., LaPre, L. F., Oatman, E. R., and Johnson, M. W. (1982). Spider mites can reduce strawberry yields. California Agriculture. 36: pp. 15-16.

Sastri, B.N. (Ed.). (1953).The wealth of India: A dictionary of Indian raw materials and industrial products. Part.III (Industrial Products).Council of Scientific \& Industrial Research, New Delhi, India, pp. 250. 
Wijesekera, R. O. B., and Jayawardena, A. L. (1973).Recent developments in the production of spices and their essential oils in Ceylon, Proc. Conf. Spices, Tropical Products Institute, London.

Xie, L., Miao, H., Xiao-Yue., and Hong. X.Y. (2006). The two-spotted spider mite Tetranychus urticae Koch and the carmine spider mite Tetranychus cinnabarinus (Boisduval) in China mixed in their Wolbachia phylogenetic tree. Zootaxa 1165: pp. 33-46.

Zhang, Z.Q. (2003). Mites of Greenhouses: Identification, Biology and Control.CABI Publishing, Wallingford.54-61 pp. http://dx.doi.org/10.1079/9780851995908.0000 